\section{Effect of Gamma Rays on the Sprouting of Stored Mangolds}

GAmma radiation, which has previously been shown to prevent sprouting in potatoes ${ }^{1}$, onions ${ }^{2}$ and carrots $^{3}$, has now been found to prevent the sprouting of stored mangolds (Beta vulgaris). Recently harvested mangolds of the variety Orange Globe, from which the leaves had been removed leaving 2 in. of leaf-stalk, were irradiated in batches of five with a cobalt-60 source giving a dose-rate of 100 rads per min. After treatment on November 7, 1956, the mangolds were bedded in damp sand in an unheated building. On April 8, 1957, the mean lengths of the sprouts were $5 \cdot 7,3 \cdot 2,1 \cdot 5,0 \cdot 0,0.0$ and 0.0 in. on the batches given $0,5,000,10,000,20,000,30,000$ and 40,000 rads, respectively. Some of the aphid species that transmit viruses of sugar beet and mangold crops survive through the winter in clamps and multiply in the spring on the developing sprouts of mangolds ${ }^{4}$. This experiment was part of a programme of research to find a method of preventing the aphid vectors from over-wintering in this way.

Rothamsted Field Station, Dunholme, Lincoln.

Technological Irradiation Group, Atomic Energy Research Establishment, Isotope Division,

Wantage Radiation Laboratory, Grove, Nr. Wantage, Borks.

'Sparrow, A. H., and Christensen, L., Nucleonics, 12, (No. 8), 16 (1954).

${ }^{2}$ Dallyn, S. L., Sawyer, R. L., anil Sparrow, A. H., Nucleonics, 13 (No. 4), 48 (1955).

3 Mikaelsen, K. Brenna, $\mathrm{H}$ and Roer, L. Proc. 1st Int. Conf. on the Peaceful Uses of Atomic Energy, i2, $208(1956 \mathrm{~A})$.

+ Broadbent, L., Cornford, C. E., Hull, R., and Tinsley, T. W., Ann. App. Biol., 36, 513 (1949).

\section{Effects of Red and Far-Red Radiation on Seed Germination}

DURING a recent study of the effect of continuous and short illumination on the germination of Amaranthus retroflexus seeds, three new facts concerning the effect of red and far-red radiation have been found.

Amaranthus retroflexus sceds germinate to the extent of about 50 per cent in darkness at $37^{\circ} \mathrm{C}$. within $48 \mathrm{hr}$. with no subsequent germinations. But a single illumination of $1,000 \mathrm{ft}$.-candles for 2 sec., given at any time after $48 \mathrm{hr}$., causes 100 per cent germination within $24 \mathrm{hr}$. of illumination. The ability of the seeds to respond to such a short light stimulus is not diminished by several months of imbibition. If, instead of darkness, the seeds were kept for the first two days in continuous highintensity far-red radiation, they did not respond even to a much stronger light stimulus. The ability of these seeds to react to a short irradiation was regained if they were placed for a certain period in darkness (Fig. 1, curve a). If, however, after being in the dark, the seeds were illuminated again with continuous far-red radiation, the ability to respond to short illumination diminished again (Fig. 1, curve $b$ ). This could be repeated several times. (For technical reasons very short illuminations (up to $60 \mathrm{sec}$.) were given with white instead of red light. But each kind of experiment was repeated at least once with pure

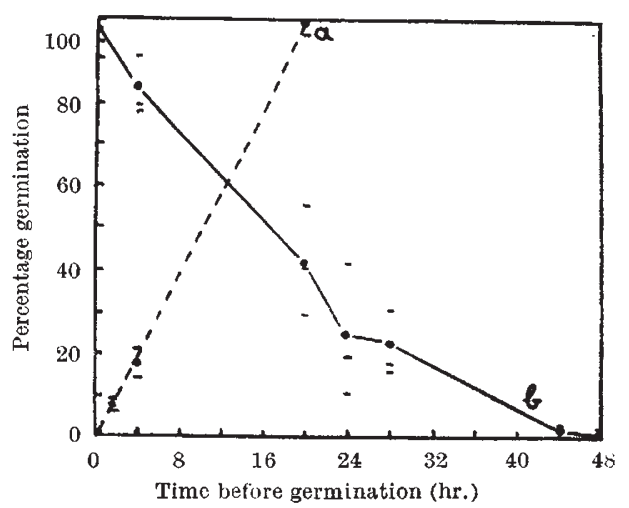

Fig. 1. (a) The seeds were kept in continuous far-red light for two days and then removed to darkness. After various intervals, which are given on the abscissa, three dishes containing 100 seeds each received an illumination of 3 sec. at 1,000 ft.-candles of
white light. Germination was counted after a further $24 \mathrm{hr}$. in darkness

(b) The seeds were kept in continuous darkness for the first two days and then removed to continuous far-red light. After various intervals in far-red light, the dishes were illuminated as above and removed to darkness for a further $24 \mathrm{hr}$. The far-red light was filtered out of a source giving an intensity of $1,000 \mathrm{ft}$.-candles at the level of the seeds

red light, to ascertain that the effect of the short illumination was really that of its red component.)

In contrast to the usual reversible red-far-red effect ${ }^{2}$, red in this case is not effective immediately after continuous high-intensity far-red. Some sort of prolonged dark reaction is needed to restore the response of the seods to red light. Thus, the effect of prolonged high-intensity light on plant development is not due only to photosynthesis, as was supposed by Liverman ${ }^{3}$ and others, but has been shown to be directly involved in the red-far-red reaction. This may also explain why Stolwijk and Zeevaart could not demonstrate an inhibitory effect of red light on the flowering of Hyoscyamus niger when the red light was used after prolonged infra-red irradiation.

The reversal of the effect of red light by farr-recl illumination was less effective if the latter was given immediately after the red than if a short interval of one or two minutes was allowed between them (Fig. 2, curve $a$ ). This indicates the existence of $i$ dark reaction during the interval. The effect of temperature on this red - dark - far-red reaction was investigated. First it was ascertained that placing the seeds for $5 \mathrm{~min}$. on ice did not affect dark germination, nor the sensitivity of the seeds to red light.

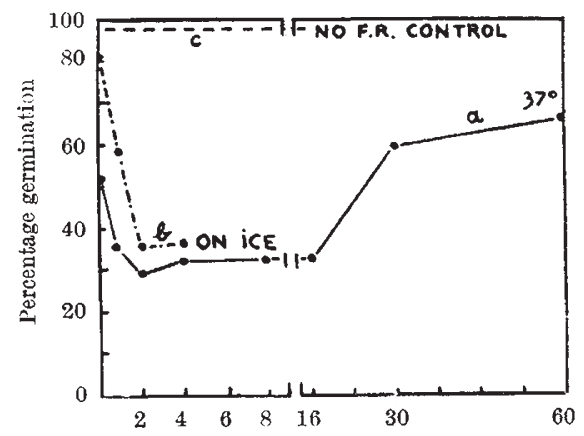

Interval ( $\mathrm{min}$ ) between red and far-red illumination

Fig. 2. Effect of temperature and time-interval between application of red and infra-red illuminations. (a) During the interva between illuminations the seeds were kept at $37^{\circ} \mathbf{C} . \quad(b)$ During the interval between illuminations the seeds were kept on 